\title{
Regression Analysis to Identification of Stable Genotypes of Finger Millet for Plant Height across India
}

\author{
M.S. Nagaraja ${ }^{1}$, G.R. Halagundegowda ${ }^{1}$, H.K. Meenakshi ${ }^{2}$ and K.N. Krishnamurthy ${ }^{3}$ \\ ${ }^{1}$ Department of Farm Engineering, Institute of Agricultural Science, Banaras Hindu University, \\ Varanasi-221005, India \\ ${ }^{2}$ Farm Section, Central Coffee Research Institute, Coffee Research Station Post, Balehonnur, \\ Koppa (T), Chikkamagalur (D), Karnataka- 577117, India. \\ ${ }^{3}$ Department of Agricultural Statistics, Applied Mathematics and Computer Science, College of \\ Agriculture, UAS, GKVK, Bangalore-560065, India \\ *Corresponding author
}

Keywords

Stability, GXE interaction,

Significant and regression coefficient.

Article Info

Accepted: 22 January 2017 Available Online: 10 February 2017
All India Co-ordinate Varietal trails conducted during kharif season of 2007, 2008 and 2009 in different testing centre's of India, original experimental set up included 10 genotypes of finger millet (Ragi) tried in 9 locations all over India with a simple randomized block design with three replications in each location. GXE interaction analysis in Eberhart and Russell model revealed highly significant differences among genotypes and environments for plant height. The genotype PR 202 was well adapted to all environments. The genotypes GPU65 and OEB57 were specially adapted to favorable environment. The genotypes OEB211 and VL333 were specially adapted to unfavorable environment.

\section{Introduction}

Finger Millet, also known as Ragi, is cultivated in drier parts of the world - mainly in Asia and Africa. It has a distinct taste and is widely used in Southern Indian and Ethiopian dishes. This is a rich source of Calcium, Iron, Protein, Fiber and other minerals. The cereal has low fat content and contains mainly unsaturated fat. It is easy to digest and does not contain gluten; people who are sensitive to gluten can easily consume Finger Millet, it consumption helps in relaxing body naturally. It is beneficial in conditions of anxiety, depression and insomnia. It is also useful for migraines, which is considered one of the most nutritious cereals; Ragi is an extremely nutritious cereal and is very beneficial for maintaining a good health. However, its high intake could increase quantity oxalic acid in the body. Therefore, it is not advised to patients having kidney stones (Urinary Calculi). Finger millet could be enjoyed in different forms and 
preparations. Roti Dosa, Porridge, Upma, Cakes, Biscuits are few popular dishes of Ragi.It has different names in local languages.

Finger millet is originally native to the Ethiopian highlands and was introduced into India approximately 4000 years ago. It is highly adaptable to higher elevations and is grown in the Himalayas up to an altitude of $2300 \mathrm{~m}$.

It is the most important small millet in the tropics (12\% of global millet area) and is cultivated in more than 25 countries in Africa (eastern and southern) and Asia (from Near East to Far East), predominantly as a staple food grain. The major producers are Uganda, India, Nepal, and China. Finger millet has high yield potential ( $>10$ t/ha under optimum irrigated conditions) and grain stores very well.

The finger millet area which was around 2.06 million hectares during 1970, s has gradually come down to 1.8 million hectares during 2005-06. However, the production has remained high and maintained around 2.7 million tones mainly because of significant raise in productivity from $1040 \mathrm{~kg} /$ ha during $1970 \mathrm{~s}$ to around $1500 \mathrm{~kg} / \mathrm{ha}$. In India, it is cultivated on 1.8 million ha, with average yields of $1.3 \mathrm{t} / \mathrm{ha}$;

Genotypic stability is an important aspect of the analysis of GXE-interaction. Its importance to plant breeders is immense. The performance of each genotype is assessed for its adoptability to the environment in which it was tested or to other environments, if they are selected at random. The criterion of assessment is that the genotype should clearly show improvements with regard to its value and use over other genotypes and must be able to retain its genetic composition. In other words, the genotype should regain the state of several years and at the same time continue to be superior in its performance.
Genotype show wide fluctuation in their yield ability when grown in different environments. The capacity of a crop to perform well over a range of environmental conditions, Stability in productivity, therefore, is a major and important consideration for the plant breeder. Study of phenotypic stability parameters is useful to identify genotypes suitable for low, marginal, average and high yielding environments. A number of statistical tools are available to estimate stability parameters with varying degree of efficiency and limitations. Realizing the importance and need for such a comprehensive study in finger millet, the present investigation.

\section{Materials and Methods}

The material for this study was taken from an evaluated data of finger millet genotypes Conducted under All India Co-ordinate Varietal trails in different testing centre's in India, Project coordinating unit (Small Millets), All India Coordinated Small Millets Improvement Project, University of Agricultural Sciences, GKVK, Bangalore during the Kharif seasons of 2007, 2008 and 2009.The original experimental set up included 10 genotypes of finger millet (Ragi) tried in 9 locations all over India under the coordinate scheme. The experimental design employed was a simple randomized block design with three replications in each location. Yield Attributing characters considered were Plant Height (X1), Number of Productive Tillers/Plant (X2), Main Ear Length (X3), Number of Fingers per Ear (X4), Days to 50\% Flowering (X5), Grain Yield (X6) and Fodder Yield (X7). Genotypes considered in the present investigation were GPU65, GPU66, GPU67, OEB265, OEB211, VR888, OEB57, PR202, VL333 and HR374. Locations were Vizianagaram (L), Jagadalpur (L2), Ranchi (L3), Bangalore (L4), Mandya (L5). Kolhapur (L6), Berhampur (L7), Coimbatore (L8) and Waghai (L9) 


\section{Methods of statistical analysis}

The significance of genotypic $\mathrm{x}$ environment interaction using the two way analysis of variance, the data was further subjected to stability analysis and structure of Pooled Two-way Analysis of Variance as below.

\begin{tabular}{|l|l|l|l|l|}
\hline Source of variation & DF & MSS & $\begin{array}{l}\text { Expected value of } \\
\text { MSS }\end{array}$ & Cal F. \\
\hline Environments & $(\mathrm{e}-1)$ & & - & - \\
Génotypes & $(\mathrm{g}-1)$ & $\mathrm{M}_{1}$ & $\sigma^{2} \mathrm{e}+\sigma^{2} \mathrm{ge}+\mathrm{e} \sigma^{2} \mathrm{~g}$ & - \\
Génotypes x Environment & $(\mathrm{g}-1)(\mathrm{e}-1)$ & $\mathrm{M}_{2}$ & $\sigma^{2} \mathrm{e}+\sigma^{2} \mathrm{ge}$ & - \\
Poolederror & $\mathrm{M}^{*}$ & $\mathrm{M}_{3}$ & $\sigma^{2} \mathrm{e}$ & - \\
\hline
\end{tabular}

* Degrees of freedom pooled over environments

MSS due to Genotypes X Environment / MSS due Pooled error $=$ Calculated $\mathrm{F}$

If calculated $\mathrm{F}$ is greater than table $\mathrm{F}$ values at corresponding to level of significance, then GXE is significantly different.

Eberhart and Russell Model:

The stability model proposed by Eberhart and Russell (1966) was adopted to analyze the data over nine environments. The model involves the estimation of three stability parameters like mean $(\bar{X})$, regression coefficient $\left(b_{i}\right)$ and deviation from regression $\left(\mathrm{S}^{2} \mathrm{~d}\right)$, which are defined by the following mathematical formula:

$\mathrm{Y}_{\mathrm{ij}}=\mu_{\mathrm{i}}+\beta_{\mathrm{i}} \mathrm{I}_{\mathrm{j}}+\delta_{\mathrm{ij}}$

Where,

$Y_{i j}$ : Mean of the $i^{\text {th }}$ genotype at the $\mathrm{j}^{\text {th }}$ environment $(i=1 \ldots .10, j=1 \ldots \ldots 9)$

$\mu_{\mathrm{i}}$ : The mean of $i^{\text {th }}$ genotype over all the environments

$\beta_{\mathrm{I}}$ : The regression coefficient that measures the response of $i^{\text {th }}$ genotype to varying environment

$\delta_{\mathrm{I}}$ : The deviation from regression of the $\mathrm{i}^{\text {th }}$ genotype of $j^{\text {th }}$ environment and $I_{j}: j^{\text {th }}$ environmental index obtained by subtracting the regression of the $i^{\text {th }}$ genotype grand mean from the mean of all genotype at $j^{\text {th }}$ environment.

\section{Stability parameters}

The mean $\left(\mu_{\mathrm{i}}\right)$, the regression coefficient $\left(\mathrm{b}_{\mathrm{i}}\right)$ and mean square deviation from linear regression line $\left(\mathrm{S}_{\mathrm{di}}^{2}\right)$ are the three stability parameters proposed by Eberhart and Russell (1966) in their stability model. These parameters were computed by using the following formula:

$\mu_{\mathrm{i}}($ mean $)=\frac{\sum_{j} Y_{i j}}{n}$

$b_{i}$

(regression coefficient $)=\frac{\sum_{j} Y_{i j} I_{j}}{\sum_{j} I_{j}^{2}}$

$\mathrm{S}^{2} \mathrm{di}$ (deviation from the regression coefficient $)=\frac{\delta_{e}^{2}}{r}-\frac{\sum_{j} \delta_{i j}^{2}}{n-2}$

Where,

$\frac{\delta_{e}^{2}}{r}$ : Mean square for (estimate of) pooled error

n: Number of environments

$\mathrm{Y}_{\mathrm{ij}}$ : Performance of $\mathrm{i}^{\text {th }}$ genotype in $\mathrm{j}^{\text {th }}$ environment 
$\Sigma_{\mathrm{j}} \delta^{2}$ ij: Sum of squares of deviations from the regression line

$\mathrm{I}_{\mathrm{j}}$ : Environmental index (i.e., environmental mean - grand

mean)

$I_{j}=\frac{\sum_{j} Y_{i j}}{v}-\frac{\sum_{i} Y_{i j}}{n v}$
Where,

$\mathrm{n}$ : Number of environments

$\mathrm{v}$ : Number of genotypes with $\Sigma_{\mathrm{j}} \mathrm{I}_{\mathrm{j}}=0$

The total variation is partitioned into genotypes, environment, environment (linear), genotype $\times$ environment (linear), pooled deviation and pooled error.

ANOVA for stability based on Eberhart and Russell Model

\begin{tabular}{|l|l|l|l|}
\hline Source & d.f. & M.S.S. & F test \\
\hline Genotype (V) & $(\mathrm{v}-1)$ & $\mathrm{MS}_{1}$ & $\mathrm{MS}_{1} / \mathrm{MS}_{3}$ \\
\hline Environment (E) & $\mathrm{v}(\mathrm{n}-1)$ & & \\
\hline Environment (E) (linear) & 1 & & \\
\hline $\begin{array}{l}\text { Genotype } \times \text { Environment } \\
(\mathrm{GXE}) \text { (linear) }\end{array}$ & $(\mathrm{v}-1)$ & $\mathrm{MS}_{2}$ & $\mathrm{MS}_{2} / \mathrm{MS}_{3}$ \\
\hline Pooled deviations & $\mathrm{v}(\mathrm{n}-2)$ & $\mathrm{MS}_{3}$ & \\
\hline Pooled error & $\mathrm{n}(\mathrm{r}-1)(\mathrm{v}-1)$ & $\mathrm{Me}$ & \\
\hline Total & $(\mathrm{nv}-1)$ & & \\
\hline
\end{tabular}

Where,

n: Number of environments

$\mathrm{v}$ : Number of genotypes

r: Number of replications

F test

(a) To test the significance of the differences among

the by genotypic means, the ' $\mathrm{F}$ ' test is given

$$
F=\frac{1}{M_{e}}\left[\frac{\sum_{j} \delta_{i j}^{2}}{n-2}\right] \sim F[1, n(r-1)(v-1)] d f
$$

Where,

$\mathrm{n}$ : Number of environments

$\Sigma_{\mathrm{j}} \delta_{\mathrm{ij}}^{2}$ : Sum of squares of deviations from the regression line

Me: Pooled error

(c) To test the hybrids/varieties not differ for the appropriate ' $t$ ' test is,

$\mathrm{t}=\frac{\hat{\mathrm{b}}_{\mathrm{i}}-1}{\mathrm{SE}(\mathrm{b})} \sim$
$\mathrm{F}=\mathrm{MS}_{1} / \mathrm{MS}_{3}$

Where,

$\mathrm{MS}_{1}$ : Mean sum of squares of varieties

$\mathrm{MS}_{3}$ : Mean sum of squares of pooled deviation

(b) To test individual from linear regression, the formula is as follows,

their regression on the environmental index, 
t-distribution with $1 \mathrm{df}$

$S E(b)=\left(\frac{\sum Y^{2}-\left\{\left(\sum Y\right)^{2} / n\right\}-b^{2} \sum(X-\bar{X})^{2}}{(n-2) \sum(X-\bar{X})^{2}}\right)^{\frac{1}{2}}$

Where,

Y: Variable or Character

$\mathrm{X}$ : Environmental index

$\mathrm{n}$ : Number of environments

$\bar{X}$ : Mean performance of the genotype over the environment

A joint consideration of the three parameters that is, over the environment $(\bar{X})$

2 . The regression coefficient $\left(b_{i}\right)$ and

3. The deviation from linear regression $\left(S^{2} d\right)$

is used to define stability of a genotype

The estimate of deviations from regression $\left(S^{2} d\right)$ suggests the degree of reliance that should be put to linear regression in interpretation of the data. If these values are significantly deviating from zero, the expected phenotype cannot be predicted satisfactorily. When the deviations $\left(S^{2} d\right)$ are not significant the conclusion may be drawn by the joint consideration of mean yield and the regression coefficient $\left(b_{i}\right)$ values as below:

1. The mean performance of the genotype

\begin{tabular}{|l|l|l|l|}
\hline $\begin{array}{l}\text { Regression } \\
\text { coefficient }\end{array}$ & Mean yield & Stability & Remarks \\
\hline$\hat{b}=1$ & High & Average & Well adapted to all environments \\
\hline$\hat{b}=1$ & Low & Average & Poorly adapted to all environments \\
\hline$\hat{b}<1$ & High & Below average & Specially adapted to favorable environments \\
\hline$\hat{b}>1$ & High & Below average & Specially adapted to unfavorable environments \\
\hline
\end{tabular}

\section{Results and Discussion}

Genotype and Environment Interaction is significantly different at $1 \%$ for Plant Height Combined over a year as presented in table 1.

Performance of Genotypes in different locations over years for plant height is presented in table 2. It was observed that the genotypes GPU 65 performed uniformly well over all the locations ( $\bar{X}=107.50, \mathrm{CV}=4.11$ ), where as OEB211 showed greater variation in plant height over all locations $(\bar{X}=104.37$, $\mathrm{CV}=12.15)$.

Among the locations, it was observed that Ranchi (L3) showed uniform plant height over all the genotypes $(\bar{X}=112.17$, $\mathrm{CV}=5.17$ ), where as Coimbatore (L8) showed greater variability with respect to genotypes ( $\bar{X}=88.80, \mathrm{CV}=9.32$ ) as presented in table 2 .

Table.1 Pooled Two-way Analysis of Variance over years for Plant Height

\begin{tabular}{|l|l|r|r|r|}
\hline \multicolumn{1}{|c|}{ Source } & \multicolumn{1}{c|}{ Df } & Sum of square & Mean sum of square & \multicolumn{1}{c|}{ F } \\
\hline Genotypes & 9 & 8100.73 & 900.08 & $108.46^{* *}$ \\
\hline Environments & 8 & 20120.00 & 2515.00 & $303.07^{* *}$ \\
\hline G XE & 72 & 4850.94 & 67.37 & $8.11^{* *}$ \\
\hline Error & 180 & 1493.684 & 8.2982 & \\
\hline Total & 269 & 34565.38 & & \\
\hline
\end{tabular}

** Significance at 1 percent 
Int.J.Curr.Microbiol.App.Sci (2017) 6(2): 1179-1186

Table.2 Performance of genotypes in different locations over years for plant height

\begin{tabular}{|c|c|c|c|c|c|c|c|c|c|c|r|}
\hline Genotypes & L1 & L2 & $\mathbf{L 3}$ & $\mathbf{L 4}$ & $\mathbf{L 5}$ & $\mathbf{L 6}$ & $\mathbf{L 7}$ & $\mathbf{L 8}$ & $\mathbf{L 9}$ & Mean & $\begin{array}{c}\text { CV } \\
(\%)\end{array}$ \\
\hline GPU65 & 106.60 & 111.57 & 106.77 & 112.10 & 113.37 & 102.73 & 105.03 & 100.30 & 108.97 & 107.50 & 4.11 \\
\hline GPU66 & 110.80 & 117.77 & 114.80 & 113.33 & 115.43 & 103.40 & 103.83 & 94.17 & 112.93 & 109.60 & 6.95 \\
\hline GPU67 & 100.90 & 96.23 & 99.87 & 94.20 & 98.33 & 89.80 & 78.17 & 70.83 & 86.80 & 90.57 & 11.43 \\
\hline OEB265 & 110.73 & 113.23 & 110.90 & 117.00 & 120.10 & 102.40 & 102.53 & 95.13 & 111.20 & 109.27 & 7.19 \\
\hline OEB211 & 119.77 & 114.07 & 114.13 & 107.23 & 114.33 & 95.00 & 90.53 & 82.80 & 101.70 & 104.37 & 12.15 \\
\hline VR888 & 118.97 & 114.87 & 112.53 & 103.00 & 109.57 & 100.67 & 93.17 & 90.07 & 97.00 & 104.43 & 9.68 \\
\hline OEB57 & 109.33 & 116.67 & 113.17 & 114.67 & 106.70 & 100.60 & 94.40 & 91.70 & 107.10 & 106.03 & 8.31 \\
\hline PR202 & 118.53 & 112.13 & 114.03 & 112.90 & 106.77 & 98.80 & 93.40 & 92.47 & 102.17 & 105.70 & 8.94 \\
\hline VL333 & 116.63 & 114.03 & 122.40 & 120.00 & 105.67 & 99.27 & 94.73 & 87.33 & 111.33 & 107.93 & 11.15 \\
\hline HR374 & 113.10 & 107.93 & 113.03 & 104.67 & 99.43 & 89.50 & 83.27 & 83.30 & 94.20 & 98.70 & 11.96 \\
\hline Mean & 112.57 & 111.83 & 112.17 & 109.90 & 108.97 & 98.23 & 93.90 & 88.80 & 103.33 & 104.43 & 4.11 \\
\hline CV (\%) & 5.41 & 5.48 & 5.17 & 6.98 & 6.41 & 5.20 & 9.19 & 9.32 & 8.32 & 5.41 & \\
\hline
\end{tabular}

Table.3 ANOVA of EBERHART and RUSSEL'S model for plant height for pooled over years

\begin{tabular}{|c|c|c|c|c|}
\hline SOURCES & DF & SSQ & MSQ & F \\
\hline Varieties & 9 & 3089.4630 & 343.2737 & $27.04^{* *}$ \\
\hline Env. +(v x E) & 80 & 15390.7815 & 192.38 & $15.15^{* *}$ \\
\hline Environment (linear) & 1 & 10866.4111 & 10866.41 & $856.02 * *$ \\
\hline Varieties X Env. (linear) & 9 & 777.95 & 86.4397 & 1.61 \\
\hline Pooled Deviation & 70 & 3746.4131 & 53.5202 & \\
\hline Variety 1 & 7 & 249.18 & 35.59 & \\
Variety 2 & 7 & 63.6398 & 9.09 & \\
Variety 3 & 7 & 343.5199 & 49.07 & \\
Variety 4 & 7 & 429.7618 & 61.39 & \\
Variety 5 & 7 & 82.0158 & 11.71 & \\
Variety 6 & 7 & 1007.0144 & 143.85 & \\
Variety 7 & 7 & 75.5025 & 10.78 & \\
Variety 8 & 7 & 316.3436 & 45.19 & \\
Variety 9 & 7 & 702.7484 & 100.39 & \\
Variety 10 & 7 & 476.6829 & 68.09 & \\
\hline Pooled Error & 180 & 2285.0089 & 12.6945 & \\
\hline Total & 89 & 18480.2445 & & \\
\hline
\end{tabular}


Table.4 Stability parameters of different models over years for plant height $(\mathrm{cm})$

\begin{tabular}{|c|c|c|c|}
\hline \multirow{2}{*}{ GENOTYPES } & \multicolumn{3}{|c|}{ EBERHART AND RUSSELLS } \\
\cline { 2 - 4 } & Mean & $\mathbf{b}_{\mathbf{i}}$ & $\mathbf{S}_{\mathbf{d}}$ \\
\hline GPU65 & 107.48 & 0.36 & 6.78 \\
\hline GPU66 & 110.35 & 0.81 & $13.05^{*}$ \\
\hline GPU67 & 90.90 & 1.28 & $12.75^{*}$ \\
\hline OEB265 & 109.23 & 0.70 & $19.61^{*}$ \\
\hline OEB211 & 104.54 & 1.36 & 5.54 \\
\hline VR888 & 104.68 & 1.07 & $17.53^{*}$ \\
\hline OEB57 & 106.02 & 0.91 & 5.24 \\
\hline PR202 & 105.83 & 1.00 & 5.30 \\
\hline VL333 & 108.03 & 1.21 & 21.45 \\
\hline HR374 & 98.34 & 1.25 & $15.45^{*}$ \\
\hline Mean & 104.54 & & \\
\hline
\end{tabular}

Over the year the genotypes GPU66, GPU67, OEB265, VR888, VL333 and HR374 are significant with respect to deviation from their respective regressions and none of the genotypes are significant with respect to regression coefficient for plant height (Table $3)$.

Genotypes GPU 65, OEB 211, OEB 57, PR202 and VL 333 are non significant for regression coefficient (bi) and non significant deviation from regression (S2di). These would be used for further stability analysis process as presented in table 4 .

In conclusion, a genotype is considered as stable if it possesses high or low mean performance in relation to genotype mean (depending on the characters), non significance of regression coefficient $\left(b_{i}\right)$ and non significance of deviation from regression $\left(\mathrm{S}_{\mathrm{di}}^{2}\right)$.

The pooled two-way analysis of variance revealed that the mean sum of squares (MSS) due to genotype $\mathrm{X}$ environment interaction were highly significant indicating the presence of variability among the characters. The variability among genotypes over different environment may be attributed to variations in temperature, relative humidity, soil type, sunshine hours etc.

For Plant Height, the genotype PR 202 was well adapted to all environments. The genotypes GPU65 and OEB57 were specially adapted to favorable environment. The genotypes OEB211 and VL333 were specially adapted to unfavorable environment.

\section{References}

Allard, R.W. and Bradshaw, A. D., 1964, Implication of genotype environmental interaction in applied plant breeding. Crop Science, 4:503-505.

Basavaraja, G.T. and Shariff, R.A., 1991, Correlation and path analysis in F2 and F3 population of finger millet (Eleusine coracana Gaertn.) genotypes at high 
hills of Garhwali Himalayas. Indian Journal of Agriculture Sciences, 71(3):205-208.

Brain Westcott, 1986, some methods of analyzing genotype environment interaction. Heredity, 24:181-200.

Chaudhari, L.B. and Acharya, R.C., 1977, Genetic variability and path co-efficient analysis of components of yield (Eleusine coracana). Experimental Agriculture, 5: 295-300.

Dhagat, N.M., Raut, N.D., Patidar, G.L. and Joshi, R.C., 1975, Stability performance of some yield attributing characters in kodo millet. Indian Journal of
Agriculture sciences, 45:293-296.

Finlay, K.W. and Wilkinson, G.N., 1963, The analysis of adaptation in a plant breeding programme. Australian Journal of Agricultural Research, 14:742-754

Mishra, H.P., Patnaik, M.C. and Naik, B. K., 1980, Variation in quantitative traits in finger millets. Indian Journal of Agricultural Sciences, 50:298-301.

Patil, H. E., 2006, Stability analysis for grain yield in finger millet (Eleusine coracana Gaertn.). International Journal of Agricultural Sciences, 74:265-275.

\section{How to cite this article:}

Nagaraja, M.S., G.R. Halagundegowda, H.K. Meenakshi and Krishnamurthy, K.N. 2017. Regression Analysis to Identification of Stable Genotypes of Finger Millet for Plant Height across India. Int.J.Curr.Microbiol.App.Sci. 6(2): 1179-1186.

doi: http://dx.doi.org/10.20546/ijcmas.2017.602.133 